\title{
CLDN3 inhibits cancer aggressiveness via Wnt-EMT signaling and is a potential prognostic biomarker for hepatocellular carcinoma
}

\author{
Lei Jiang ${ }^{1, *}$, Yi-Dong Yang ${ }^{1,2, *}$, Li Fu ${ }^{1}$, Weiqi Xu${ }^{1}$, Dabin Liu ${ }^{1}$, Qiaoyi Liang ${ }^{1}$, Xiang \\ Zhang $^{1}$, Lixia $X \mathbf{u}^{1}$, Xin-Yuan Guan ${ }^{3}$, Bin Wu ${ }^{2}$, Joseph J.Y. Sung ${ }^{1}$ and Jun $\mathbf{Y u}^{1}$ \\ ${ }^{1}$ Institute of Digestive Disease and Department of Medicine and Therapeutics, State Key Laboratory of Digestive Disease, \\ CUHK Shenzhen Research Institute, Li Ka Shing Institute of Health Sciences, The Chinese University of Hong Kong, Shatin, \\ N.T., Hong Kong \\ ${ }^{2}$ Department of Gastroenterology, The Third Affiliated Hospital, Sun Yat-sen University, Guangzhou, China \\ ${ }^{3}$ Department of Clinical Oncology, The University of Hong Kong, Hong Kong, China \\ * These authors contributed equally to this work
}

Correspondence to: Jun Yu, email: junyu@cuhk.edu.hk

Keywords: CLDN3, hepatocellular carcinoma, metastasis, survival

Received: June 25, $2014 \quad$ Accepted: July 31, $2014 \quad$ Published: July 31, 2014

This is an open-access article distributed under the terms of the Creative Commons Attribution License, which permits unrestricted use, distribution, and reproduction in any medium, provided the original author and source are credited.

\section{ABSTRACT}

Hepatocellular carcinoma (HCC) is one of the most common fatal malignancies but the molecular genetic basis of this disease remains unclear. By using genomewide methylation profiling analysis, we identified CLDN3 as an epigenetically regulated gene in cancer. Here, we investigated its function and clinical relevance in human HCC. CLDN3 downregulation occurred in 87/114 (76.3\%) of primary HCCs, where it was correlated significantly with shorter survival of HCC patients $(P=0.021)$. Moreover, multivariate cyclooxygenase regression analysis showed that CLDN3 was an independent prognostic factor for overall survival $(P=0.014)$. Absent expression of CLDN3 was also detected in $67 \%$ of HCC cell lines, which was significantly associated with its promoter hypermethylation. Ectopic expression of CLDN3 in HCC cells could inhibit cell motility, cell invasiveness, and tumor formation in nude mice. Mechanistic investigations suggested through downregulation of GSK3B, CTNNB1, SNAI2, and $C D H 2, C L D N 3$ could significantly suppress metastasis by inactivating the Wnt/ $\beta$ catenin-epithelial mesenchymal transition (EMT) axis in HCC cells. Collectively, our findings demonstrated that CLDN3 is an epigenetically silenced metastasis suppressor gene in HCC. A better understanding of the molecular mechanism of CLDN3 in inhibiting liver cancer cell metastasis may lead to a more effective management of HCC patients with the inactivation of CLDN3.

\section{INTRODUCTION}

Hepatocellular carcinoma (HCC) is the fifth most common malignancy in the world and the second leading cause of cancer death in Asia [1]. HCC is associated with multiple risk factors and is now recognized as a both genetic and epigenetic disease [2,3]. While the sequential accumulation of various genetic changes in hepatocarcinogenesis has been extensively studied, the contribution of epigenetic alterations to HCC development and progression has remained relatively poorly understood. Compelling evidence reveals that aberrant DNA methylation is a frequent event in HCC. Many studies showed that differentially methylated genes and CpG island methylator phenotype (CIMP) status in HCC were associated with clinicopathological features. Some commonly studied tumor suppressor genes (TSGs), such as RASSF1A, p16, SOCS1, GSTP1 and CDH1, have been found to be hypermethylated in HCC in a cancer-specific manner, suggesting that aberrant DNA methylation is an essential incident for hepatocarcinogenesis [4].

Using methylated DNA immunoprecipitation 
Table 1: Association between CLDN3 mRNA expression and clinicopathologic characteristics of patients with HCC $(n=114)$

\begin{tabular}{|c|c|c|c|c|}
\hline Clinical features & Number & CLDN3 (-) & CLDN3 (+) & $P$-value \\
\hline $\begin{array}{l}\text { Gender } \\
\text { Female } \\
\text { Male }\end{array}$ & $\begin{array}{l}21 \\
93\end{array}$ & $\begin{array}{l}17(81.0 \%) \\
70(75.3 \%)\end{array}$ & $\begin{array}{l}4(19.0 \%) \\
23(24.7 \%)\end{array}$ & 0.580 \\
\hline $\begin{array}{l}\text { Age }(\mathrm{yrs}) \\
<60 \\
>60\end{array}$ & $\begin{array}{l}97 \\
17\end{array}$ & $\begin{array}{l}73(75.3 \%) \\
14(82.4 \%)\end{array}$ & $\begin{array}{l}24(24.7 \%) \\
3(17.6 \%)\end{array}$ & 0.526 \\
\hline $\begin{array}{l}\text { HbsAg } \\
\text { Negative } \\
\text { Positive }\end{array}$ & $\begin{array}{l}18 \\
90 \\
\end{array}$ & $\begin{array}{l}16(88.9 \%) \\
66(73.3 \%) \\
\end{array}$ & $\begin{array}{l}2(11.1 \%) \\
24(26.7 \%)\end{array}$ & 0.159 \\
\hline $\begin{array}{l}\text { Serum AFP }(\mathrm{ng} / \mathrm{ml}) \\
<400 \\
>400\end{array}$ & $\begin{array}{l}59 \\
48\end{array}$ & $\begin{array}{l}43(72.9 \%) \\
37(77.1 \%)\end{array}$ & $\begin{array}{l}16(27.1 \%) \\
11(22.9 \%)\end{array}$ & 0.619 \\
\hline $\begin{array}{l}\text { Tumor size }(\mathrm{cm}) \\
<5 \\
>5\end{array}$ & $\begin{array}{l}48 \\
62\end{array}$ & $\begin{array}{l}39(81.2 \%) \\
44(71.0 \%)\end{array}$ & $\begin{array}{l}9(18.8 \%) \\
19(29.0 \%)\end{array}$ & 0.214 \\
\hline $\begin{array}{l}\text { Cirrhosis } \\
\text { Absent } \\
\text { Present }\end{array}$ & $\begin{array}{l}76 \\
32\end{array}$ & $\begin{array}{l}57(75.0 \%) \\
24(75.0 \%)\end{array}$ & $\begin{array}{l}19(25.0 \%) \\
8(25.0 \%)\end{array}$ & 1.000 \\
\hline $\begin{array}{l}\text { Differentiation } \\
\text { Well differentiated (I) } \\
\text { Moderately differentiated (II) } \\
\text { Poorly differentiated (III-IV) }\end{array}$ & $\begin{array}{l}15 \\
45 \\
46\end{array}$ & $\begin{array}{l}12(80.0 \%) \\
34(75.6 \%) \\
34(73.9 \%)\end{array}$ & $\begin{array}{l}3(20.0 \%) \\
11(24.4 \%) \\
12(26.1 \%)\end{array}$ & 0.893 \\
\hline $\begin{array}{l}\text { Recurrence or Metastasis } \\
\text { Absent } \\
\text { Present }\end{array}$ & $\begin{array}{l}57 \\
54\end{array}$ & $\begin{array}{l}46(80.7 \%) \\
38(70.4 \%)\end{array}$ & $\begin{array}{l}11(19.3 \%) \\
16(29.6 \%)\end{array}$ & 0.205 \\
\hline $\begin{array}{l}\text { TNM stage (AJCC) } \\
\text { Early (I-II) } \\
\text { Advanced (III-IV) }\end{array}$ & $\begin{array}{l}74 \\
20 \\
\end{array}$ & $\begin{array}{l}55(74.3 \%) \\
14(70.0 \%) \\
\end{array}$ & $\begin{array}{l}19(25.7 \%) \\
6(30.0 \%) \\
\end{array}$ & 0.698 \\
\hline
\end{tabular}

Table 2: Association of various factors with overall survival in $114 \mathrm{HCCs}$ determined by COX regression model.

\begin{tabular}{|c|c|c|c|c|c|}
\hline & & Univariate analysis & & Multivariate analysis & \\
\hline \multicolumn{2}{|l|}{ Variable } & $\operatorname{HR}^{\mathrm{a}}\left(95 \% \mathrm{CI}^{\mathrm{b}}\right)$ & $P^{\mathrm{c}}$ & $\mathrm{HR}(95 \% \mathrm{CI})$ & $P$ \\
\hline Gender & Male vs. Female & $0.560(0.238-1.314)$ & 0.183 & - & - \\
\hline Age & $\leq 60 \mathrm{yr}$ vs. $>60 \mathrm{yr}$ & $0.987(0.958-1.017)$ & 0.388 & - & - \\
\hline Tumor diameter & $\leq 5 \mathrm{~cm} \mathrm{vs.}>5 \mathrm{~cm}$ & $1.146(0.560-2.343)$ & 0.709 & - & - \\
\hline Cirrhosis & Absent vs. Present & $1.420(0.671-3.002)$ & 0.359 & - & - \\
\hline Differentiation & Well-Moderate vs. Poor & $1.742(1.006-3.018)$ & 0.048 & $1.785(0.981-3.248)$ & 0.058 \\
\hline Recurrence & Absent vs. Present & $3.337(1.491-7.470)$ & 0.003 & $5.431(2.034-14.503)$ & 0.001 \\
\hline TNM stage & Early vs. Advanced & $2.315(1.013-5.290)$ & 0.047 & $2.237(0.870-5.751)$ & 0.095 \\
\hline CLDN3 expression & Reduced vs. Normal & $0.308(0.107-0.885)$ & 0.029 & $0.247(0.082-0.749)$ & 0.014 \\
\hline
\end{tabular}

${ }^{\mathrm{a}} \mathrm{HR}$ : hazard ratio for death.

${ }^{\mathrm{b}} \mathrm{CI}$ : Confidence interval.

${ }^{\mathrm{c}} \mathrm{P}<.05$ was considered statistically significant (in bold). 
coupled with DNA microarray (MeDIP-chip) analysis, we have identified that $C L D N 3$ was preferentially methylated in cancer [5]. CLDN3 is located on Chromosome $7 q 11.23$ and belongs to a family of proteins involved in the formation and function of tight junctions (TJs). It's well known that TJs function as the most topical barrier structure to fluid and cells in epithelial and endothelial cells. Disruption of TJs can trigger malignant transformation in a wide variety of epithelial cell types [6]. Early studies demonstrated that TJs were disorganized in HCC cells due to poor differentiation of the hepatocytes [7] and later studies found the disruption of TJ barrier could facilitate dissociated cancer cells to metastasize $[8,9]$. The backbones of TJs are mainly composed by occludins and claudins between adjacent cells. The dimerization of these trans-membrane proteins form a zipper-like structure to constrict the paracellular space to prevent solutes and water from passing through. The 24 members from human CLDN protein family are expressed in a tissue-specific pattern. Recent studies have reported CLDN family members in a wide range of human cancers and found these types of proteins are also expressed in a tumor-specific manner [10]. For instance, low expression of CLDN1 has been reported to be associated with progression and metastasis in breast and prostate cancer $[11,12]$ while the elevated expression of CLDN1 exhibited structural and functional changes of epithelial to mesenchymal transition (EMT) -an important molecular event of metastasis [13]. Similarly, CLDN7 is highly expressed in renal cell carcinoma [14] but lost in invasive ductal carcinomas of the breast and in head and neck cancer $[15,16]$. These studies suggest the contribution of overexpression/loss of CLDNs in tumorigenesis may trigger different mechanisms and their expression pattern may be highly tissue-specific in different cancerous tissues.

In this study, we initially examined the expression level of CLDN3 in human HCC cell lines and clinical HCC samples, as well as its correlation with promoter methylation status. Both in vitro and in vivo assays were used to study the tumor suppressive function of CLDN3. In addition, the tumor-suppressive mechanism of CLDN3 and its clinical significance in $\mathrm{HCC}$ was also investigated.

\section{RESULTS}

\section{CLDN3 is frequently downregulated in HCC}

Semi-quantitative RT-PCR was initially used to study the mRNA expression status of CLDN3 in $9 \mathrm{HCC}$ cell lines, 4 normal human liver tissues, and 52 primary HCCs and their paired adjacent normal tissues (Cohort 1). CLDN3 was significantly downregulated in 6/9 (66.7\%) of HCC cell lines (HepG2, Hep3B, Huh7, Bel7404, SNU398, and PLC5) but was readily expressed in all 4 normal liver tissues (Fig. 1A). Expression of CLDN3 was observed in all 52 tested adjacent normal tissues, whereas reduced expression of CLDN3 was detected in 33/52 (63.5\%) of primary HCCs (Fig. 1B). Protein expression level of CLDN3 was also studied by immunohistochemistry (IHC) staining in paraffin sections of 19 primary HCCs and their adjacent normal tissues obtained from Cohort 1 (Fig. 1C). Based on the score of staining, the average protein level of CLDN3 was significantly lower in HCC tumor tissues than that in adjacent normal tissues (1.2 vs. 2.4; $\mathrm{P}<0.0001$; Fig.1D). Moreover, quantitative real-time PCR (qPCR) was performed to examine the mRNA expression level of CLDN3 in 114 primary HCCs and their adjacent normal liver tissues (Cohort 2). Similarly, downregulation of CLDN3 was detected in 87/114 (76.3\%) of primary HCCs compared with their normal counterparts (defined as a 2-fold decrease of CLDN3 expression in tumors) (Fig. 1E).

\section{$C L D N 3$ is an independent predictor of poor survival in HCC patients}

The correlation between $C L D N 3$ expression status and clinicopathologic features of 114 HCCs was further evaluated, which was summarized in Table 1 . The results showed that no correlation was observed between $C L D N 3$ downregulation and patient's gender, age, $\mathrm{HbsAg}$, serum AFP, tumor size, cirrhosis, tumor cell differentiation, recurrence and tumor stage. However, Kaplan-Meier survival analysis showed that the overall 5-year survival rate was significantly lower in informative HCC patients with $C L D N 3$ downregulation $(\mathrm{n}=82$, with a mean of 60 months) than that in HCC patients with normal CLDN3 expression ( $\mathrm{n}=27$, with a mean of 78 months $)(\mathrm{P}=0.021$, Fig. 1F). By univariable analysis, downregulation of CLDN3 $(\mathrm{P}=0.029)$, presence of recurrence $(\mathrm{P}=0.003)$, poor differentiation $(\mathrm{P}=0.048)$, and advanced clinical stage $(\mathrm{P}=0.047)$ were significant negative prognostic factors for overall survival in HCC patients (Table 2). Nevertheless, multivariate analysis showed that downregulation of CLDN3 ( $\mathrm{P}=0.014)$ and recurrence $(\mathrm{P}=0.001)$ were two independent prognostic predictors for $\mathrm{HCC}$ patients (Cohort 2) enrolled in this study (Table 2).

\section{Promoter methylation of $C L D N 3$ is correlated with its transcriptional inactivation}

To determine whether aberrant promoter methylation could contribute to downregulation of CLDN3 in HCC, we treated 3 HCC cell lines with absent expression of CLDN3 (HepG2, Hep3B, and PLC5) with the demethylating agent 5-Aza. The results showed expression of $C L D N 3$ was restored in all $3 \mathrm{HCC}$ cell lines examined (Fig. 2A), suggesting that inactivation of $C L D N 3$ in HCC may be caused by its promoter 
methylation. The methylation status of CLDN3 promoter was analyzed by MSP. Complete or partial methylation was detected in $6 \mathrm{HCC}$ cell lines with absent expression of CLDN3 (HepG2, Hep3B, Huh7, Bel7404, SNU398, and PLC5), whereas no or weak methylation was detected in other 3 HCC cell lines (Huh1, Huh6, and SNU449) and 4 normal liver tissues with CLDN3 expression (Fig. 2B). To further explore the methylation details of CLDN3 in $\mathrm{HCC}, 6 \mathrm{HCC}$ cell lines with different degrees of
CLDN3 methylation were characterized by BGS. In line with the MSP results, the highest density of methylated CpG sites was found in Bel7404 and PLC5 cells with complete $C L D N 3$ methylation, whereas no methylated CpG sites was found in Huh6, SNU449 and normal liver tissues with strong CLDN3 unmethylation (Fig. 2C). These results demonstrated that hypermethylation of the CLDN3 promoter was associated with its transcriptional repression.

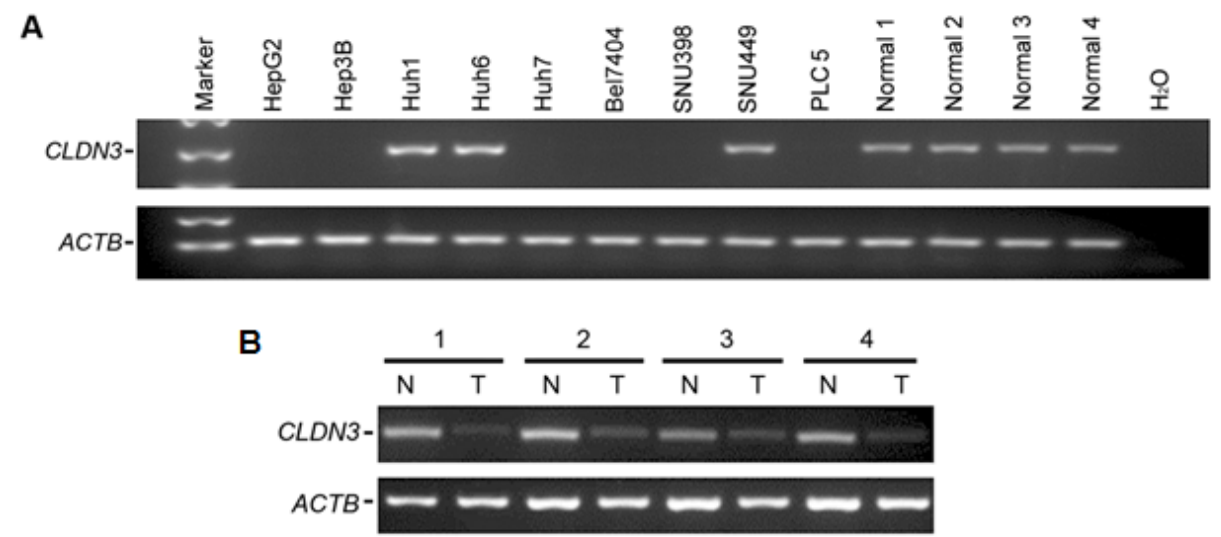

C

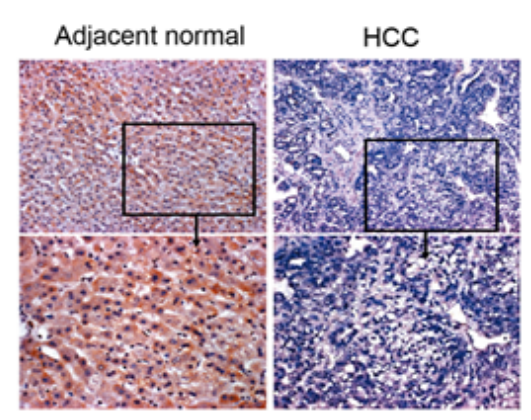

E

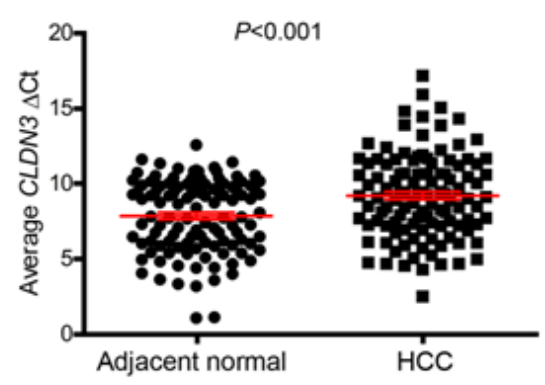

D

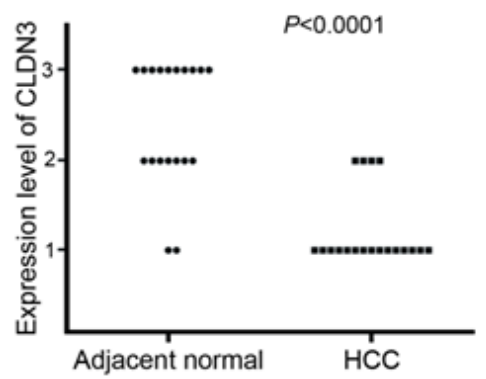

F

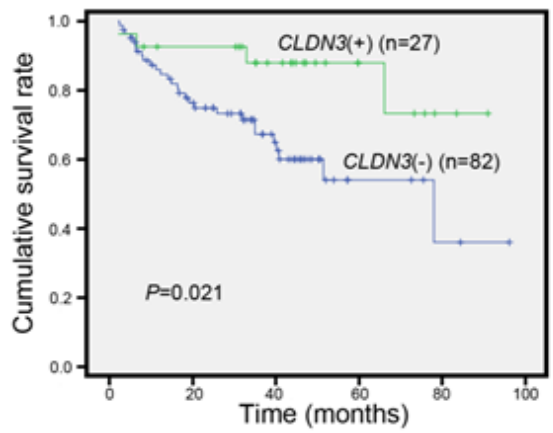

Fig.1: Downregulation of $C L D N 3$ in HCC. (A) CLDN3 expression was frequently down-regulated in HCC cell lines (A) and primary HCCs (cohort 1) (B) detected by RT-PCR. For primary HCCs, expression of CLDN3 in tumor tissues (T) was compared with their paired nontumorous tissues $(\mathrm{N})$. ACTB was used as a loading control. (C) Representative images of CLDN3 protein expression in a pair of HCC (right) and its adjacent normal tissue (left) determined by immunohistochemistry (IHC) with anti-CLDN3 antibody (brown). The slide was counterstained with hematoxylin. Original magnification, x200 (upper); x400 (lower). (D) CLDN3 protein expression level was indicated by IHC score according to the percentage of CLDN3 positive cells in primary HCC tumor tissues and their adjacent normal tissues $(1,<20 \% ; 2,20-50 \% ; 3,>50 \%)$. (E) CLDN3 expression was frequently down-regulated in primary HCCs (cohort 2$)$ detected by qPCR. Dot plots represent the $\triangle \mathrm{Ct}$ values of $C L D N 3$ (higher $\triangle \mathrm{C}_{\mathrm{T}}$ values correspond to lower expression; Mean $\pm \mathrm{SEM}$; Mann-Whitney $\mathrm{U}$ test). (F) Kaplan-Meier curves for overall survival rate of patients with HCC according to the expression level of CLDN3. Green, patients with normal $C L D N 3$ expression ( $\mathrm{n}=27$, mean survival time $=78$ months); Blue, patients with lower expression of $C L D N 3$ ( $\mathrm{n}=82$, mean survival time $=60$ months, $\mathrm{P}=0.021$ ) 
We next investigated the methylation frequency of CLDN3 promoter in 30 primary HCC tumors and their paired adjacent normal tissues by MSP. Methylation of $C L D N 3$ was detected in $18 / 30(60.0 \%)$ of the primary HCCs compared with their normal counterparts (Fig. 2D).

\section{Ectopic expression of $C L D N 3$ induces cobblestone- like morphology change and suppresses foci formation in HCC cells}

To determine if CLDN3 has tumor-suppressive function, stably CLDN3-expressing clones were established from HepG2 and Huh7 cells. CLDN3 gene and protein expression in these clones were confirmed by RTPCR and Western blot analyses (Fig. 3A,B). The CLDN3transfected HCC cells displayed an obvious morphological change compared with control cells. As shown in Fig. 3C, empty vector-transfected $\mathrm{HCC}$ cells grew in a normal state of monolayer culture while CLDN3-transfected cells formed cobblestone-like colonies (Fig. 3C). Ectopic expression of CLDN3 in these HCC cells also caused a significant decrease in cell foci formation. The number of foci formed in CLDN3-transfected cells were significantly reduced than those in empty vector-transfected cells (down to $48 \%-63 \%$ of vector control, $\mathrm{P}<0.01$, Fig. $3 \mathrm{D}$ ). However, no obvious difference was observed between CLDN3- and empty vector-transfected HepG2 and Huh7 cells by cell proliferation, cell cycle and cell apoptosis analyses (Fig. $\mathrm{S} 1, \mathrm{P}>0.05)$.

\section{Metastasis suppressing ability of $C L D N 3$ in $\mathrm{HCC}$ cells}

Since CLDN3 is a tight junction (TJ) protein and disruption of TJ barrier could facilitate dissociated cancer cells to metastasize [9], we thus determine the metastatic

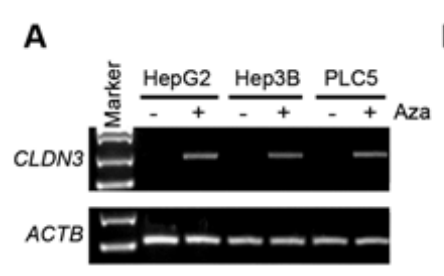

B
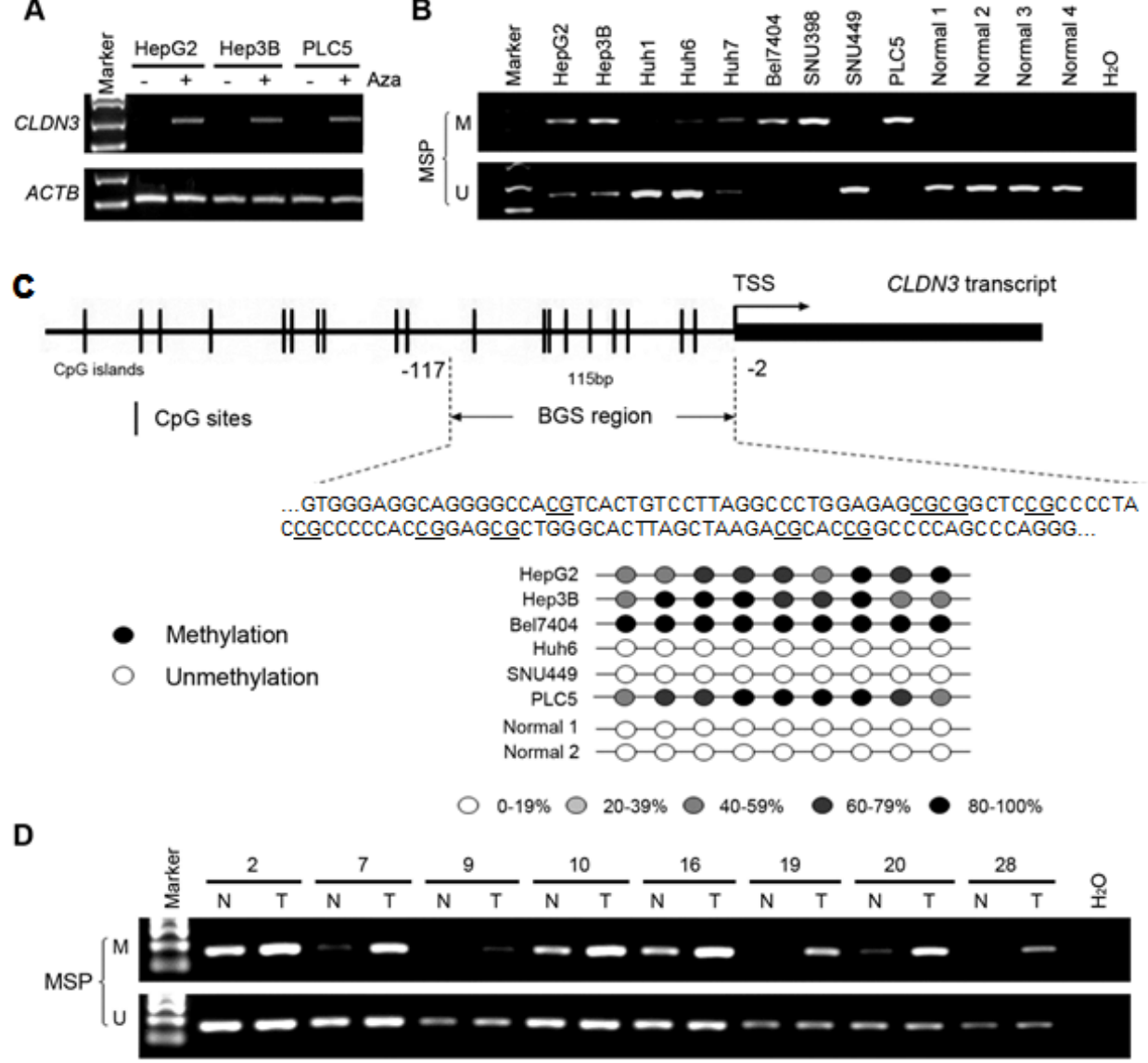

Fig.2: CLDN3 promoter methylation status in HCC. (A) $C L D N 3$ was restored after treatment with demethylating agent 5-aza2'deoxycytidine (Aza) in three HCC cell lines without endogenous CLDN3 expression. (B) Promoter methylation of CLDN3 in HCC cell lines and normal liver tissues was determined by methylation specific PCR (MSP). (C) Representative high-resolution methylation profiles obtained by bisulfite sequencing of BGS region (-117 to -2), comprised of 9 CpG sites in the CLDN3 promoter, in randomly selected 6 $\mathrm{HCC}$ cell lines and 2 normal liver tissues. For each sequenced DNA sample, the percentage methylation of each CpG was defined as the percentage of methylated CpGs from 6-8 randomly sequenced clones. Black circle, $80-100 \%$ methylated CpG; White circle, $0-19 \%$ methylated CpG; Light grey circle, 20-39\% methylated CpG; Grey circle, 40-59\% methylated CpG; Dark grey circle, 60-79\% methylated CpG. (D) Representative MSP results of $C L D N 3$ in paired primary HCC (T) and adjacent normal (N) tissues. 
role of CLDN3 in HCC cells by wound-healing assays and Boyden chamber matrigel invasion assays. Ectopic expression of CLDN3 could significantly suppress the migration in CLDN3-transfectants compared with control cells in HepG2 $(58.7 \% \pm 1.0 \%$ vs. $74.1 \% \pm 0.4 \%, \mathrm{P}<0.01)$ and in Huh7 $(5.0 \% \pm 0.8 \%$ vs. $42.1 \% \pm 0.7 \%, \mathrm{P}<0.001$; Fig. 4A). Similarly, CLDN3 could also significantly inhibit the invasion in CLDN3-transfectants compared with control cells by invasion assays in HepG2 $(29.8 \%$ $\pm 0.1 \%$ of control cells, $\mathrm{P}<0.001)$ and in Huh7 $(52.2 \%$ $\pm 0.2 \%$ of control cells, $\mathrm{P}<0.05$; Fig. $4 \mathrm{~B}$ ). To further confirm the metastasis suppressing ability of CLDN3 in HCC cells, RNAi was used to knockdown endogenous $C L D N 3$ expression in Huh6 cells. The result showed that
siRNA against $C L D N 3$ could significantly reduce $C L D N 3$ expression in Huh6 cells (Fig. S2). Twenty-four hours post siCLDN3 transfection, both wound-healing and invasion assays showed a significant increase of the cell migration $(\mathrm{P}<0.05$, Fig. 4A3,4) and invasion ability $(\mathrm{P}<0.01$, Fig. $4 \mathrm{~B} 3,4)$ in $C L D N 3$-knockdown Huh6 cells compared with control cells.

\section{Ectopic expression of $C L D N 3$ inhibits tumor growth in nude mice}

To further explore the in vivo tumor suppressive ability of $C L D N 3$, tumor formation in nude mouse was
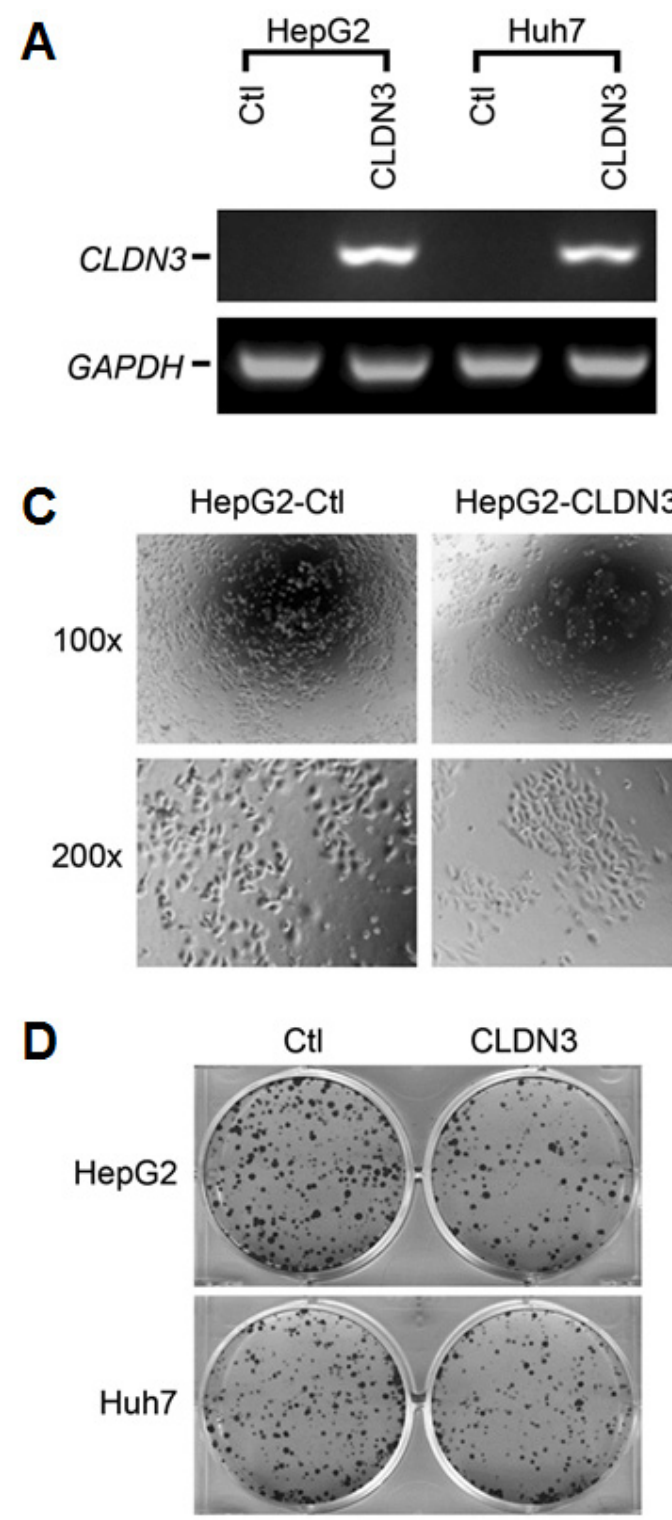

B
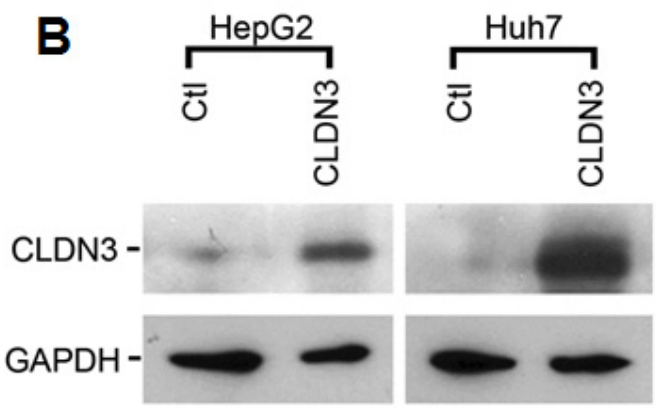

HepG2-CLDN3
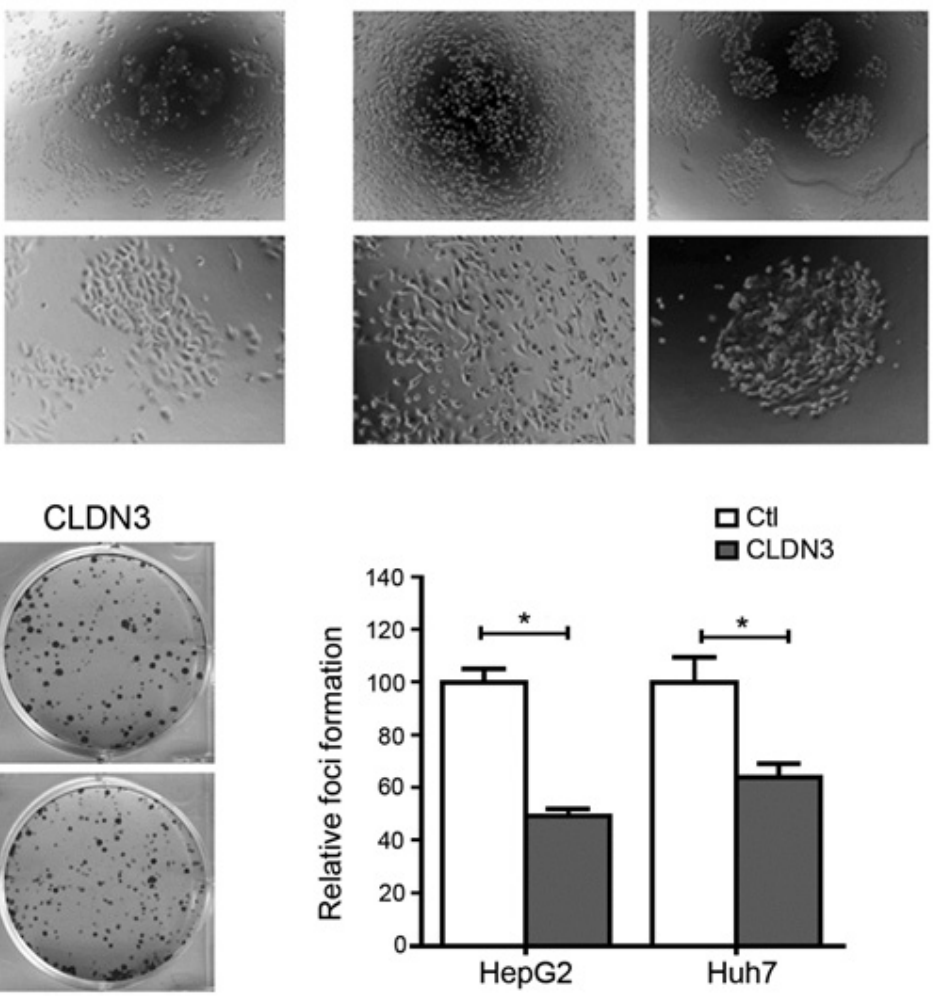

Fig.3: Morphological change and foci inhibition role of $C L D N 3$ in HCC cells. Ectopic expression of CLDN3 in HCC cell lines (HepG2 and Huh7) was confirmed by RT-PCR (A) and western blot (B). (C) Representatives of cell morphology of CLDN3-expressing cells (HepG2-CLDN3/Huh7-CLDN3) and control cells (upper, original magnification $\times 100$; lower, $\times 200)$. (D) Representative of foci formation in monolayer culture. Quantitative analyses of foci numbers were shown in the right panel. Values were the mean \pm SD of at least three independent experiments. ${ }^{*} \mathrm{P}<0.05$; independent Student's $t$-test. 
tested by injection of Huh7-CLDN3 cells $(n=5)$, while Huh7-Ctl cells $(n=5)$ were used as controls. Within 17 days, solid tumors were readily visible in right hind legs of all 10 mice injected with Huh7-CLDN3 cells and Huh7-Ctl cells, respectively (Fig. 5A). The mean tumor weight was significantly less in Huh7-CLDN3 inoculated nude mice than those in Huh7-Ctl cells injected nude mice (159.2 $\pm 34.2 \mathrm{mg}$ vs. $36.6 \pm 10.9 \mathrm{mg}, \mathrm{P}<0.01$, Fig. $5 \mathrm{~B}$ ). Moreover, the size of tumors caused by Huh7-CLDN3 cells was significantly smaller than tumors induced by Huh7-Ctl cells (tumor volume: $40.0 \pm 11.9 \mathrm{~mm}^{3}$ vs. $7.10 \pm 3.22 \mathrm{~mm}^{3}$, $\mathrm{P}<0.0001$, Fig. 5C). These results demonstrated that
$C L D N 3$ has a strong tumor suppressive ability in vivo.

\section{CLDN3 inactivates WNT-EMT signaling pathways in $\mathrm{HCC}$ cells}

To explore the mechanism underlying metastasis inhibition by $C L D N 3$, deregulated genes involved in Wnt signaling between CLDN3-transfected HepG2 cells and control cells were determined by Wnt signaling pathway PCR array. From the $84 \mathrm{Wnt}$ pathway related genes, 5 were decreased (GSK3B, CCDN1, CTNNB1,
A1

동

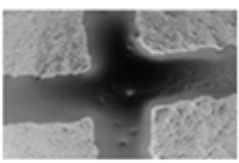

寺

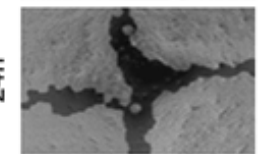

A3

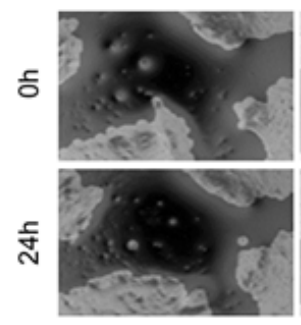

Huh6-Ctl

B1

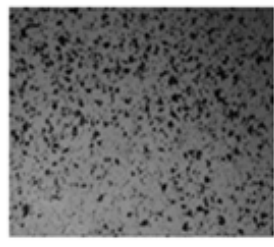

B3

HepG2-CtI

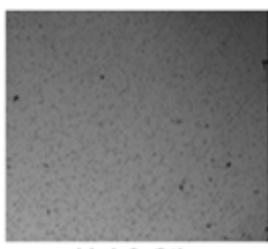

Huh6-Ctl

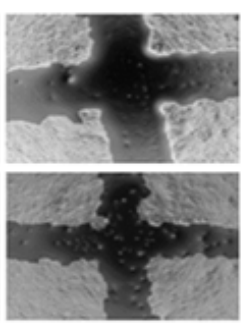

HepG2-CLDN3

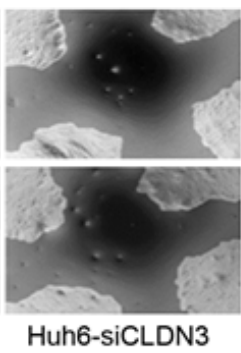

Huh6-siCLDN3

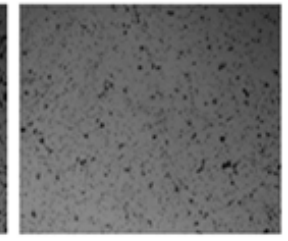

HepG2-CLDN3

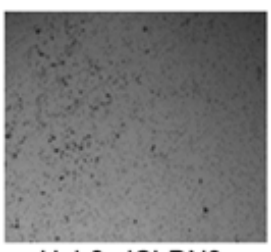

Huh6-siCLDN3

A2

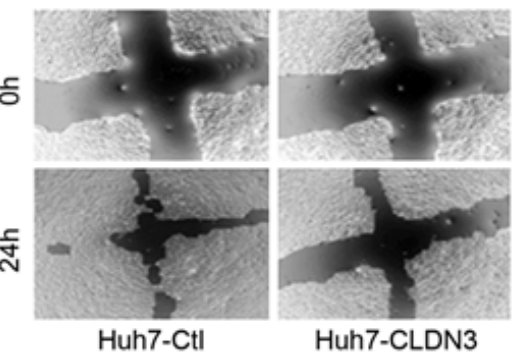

A4

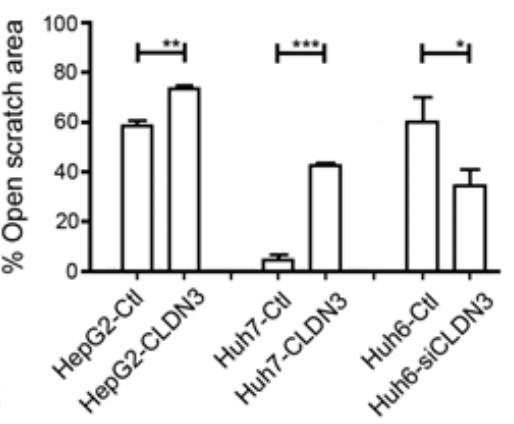

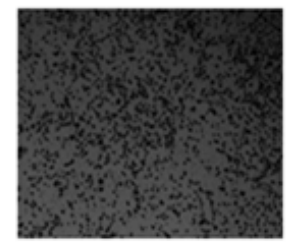

Huh7-Ctl

B4

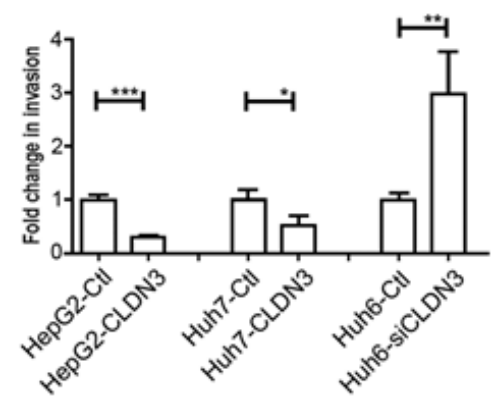

Fig.4: CLDN3 inhibits cell mobility and invasiveness in HCC cells. (A1-3) The effect of CLDN3 on cell migration was determined by wound-healing assay. During a period of 24h, the spreading speed of CLDN3-expressing cells (HepG2-CLDN3/Huh7-CLDN3) along the wound edge was slower than that in control cells (HepG2-Ct1/Huh7-Ct1, A1-2); while knockdown of CLDN3 in Huh6 cells by siRNA significantly promoted the cell mobility (A3). (A4) The percentage of open wound area was quantified in the right panel. (B1-3) Ectopic expression of $C L D N 3$ significantly inhibited the invasion ability in HepG2 (B1) and Huh7 (B2) cells; while knockdown of CLDN3 by siRNA significantly promoted the invasion in Huh-6 cells (B3) by Boyden chamber matrigel invasion assay. (B4) The number of invaded tumor cells was quantified in the right panel. ( ${ }^{*} \mathrm{P}<0.1, * * \mathrm{P}<0.05$, *** $\left.\mathrm{P}<0.01\right)$ 
SLC9A3R1, and CSNK1D) and one (FZD3) was increased significantly (fold change $>3, \quad \mathrm{P}<0.05$ ) in HepG2CLDN3 cells compared with HepG2-Ctl cells (Fig. 6A). Two significantly downregulated key modulators of the canonical Wnt pathway $G S K 3 B$ (-5.28 fold) and $C T N N B 1$ ( -3.25 fold) were further verified by qPCR in CLDN3-transfected HepG2 and MHCC97H (a wellknown metastatic HCC cell line), as well as in CLDN3knockdown Huh6 cells (Fig. 6B). Furthermore, the correlation between $C L D N 3$ expression and Wnt pathway induced molecules related to epithelial-mesenchymal transition (EMT) were also examined by qPCR. Among the 6 genes tested (CDH1, CDH2, CTNNB1, ZEB1, SNAI1, and $S N A I 2)$, one EMT-inducing transcription factor (SNAI2) and one mesenchymal marker (CDH2) showed significant negative correlation with $C L D N 3$ expression in CLDN3- knockdown or overexpression HCC cells (Fig. 6C). The protein level change of EMT markers in CLDN3knockdown/overexpression HCC cells were further confirmed by western blotting. Expression of E-cadherin (encoded by $C D H 1), \beta$-catenin (encoded by CTNNB1), active $\beta$-catenin, mesenchymal marker $\mathrm{N}$-cadherin (encoded by $\mathrm{CDH} 2$ ) and Slug (encoded by SNAI2) showed significant negative-correlation with CLDN3 expression in Huh6 and HepG2 cells (Fig. 6D), suggesting that CLDN3 could act as a negative regulator of the WNT-EMT signaling pathways in hepatocarcinogenesis.

\section{DISCUSSION}

CLDN3 belongs to a family of proteins important in tight junction formation and function. Recently, it has become apparent that $C L D N$ gene expression is frequently altered in several human cancers [17], its expression pattern and biological function are largely unrevealed in human liver cancer. Here, for the first time, we showed that $C L D N 3$ was frequently downregulated in human liver cancer and its downregulation was significantly associated with poor survival of HCC patients. We found that reduced expression of $C L D N 3$ was caused by promoter hypermethylation in HCC cells. This is in line with previous studies demonstrating that the expression level of $C L D N 3$ was epigenetically regulated by promoter methylation in esophageal cancer [18] and ovarian cancer cells [19]. The expression of other claudin family members, such as CLDN1 in podocyte [20] and breast cancer [21] and CLDN4 in bladder cancer [22], has also been reported to be regulated through promoter hypermethylation.

It has been widely accepted that disruption of TJ barrier is a common event in various human cancers and loss of TJ function is correlated to cancer progression and metastasis [23]. Disassembly of TJs can cause loss of cell polarity and increased cell invasiveness [23, 24]. The claudin family proteins are known to form the "backbone" of TJs between cells and their expression profile in

\section{A}
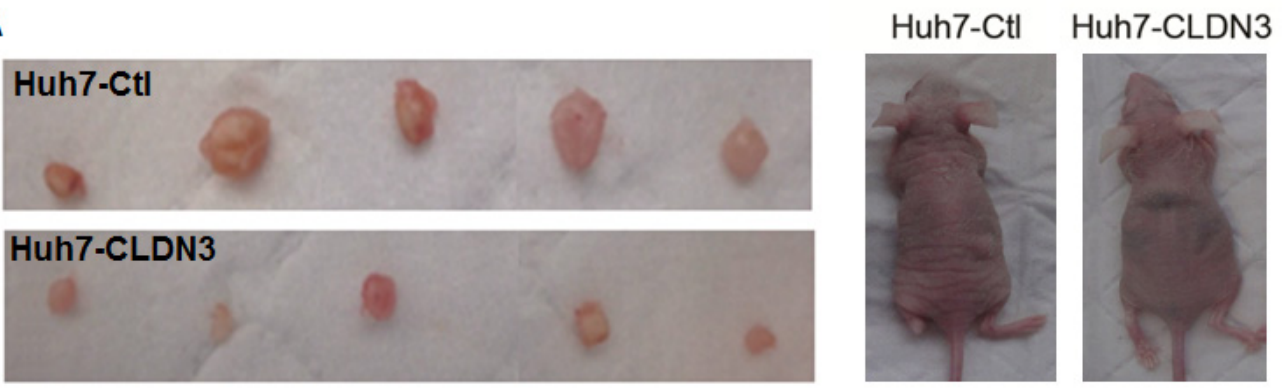

B

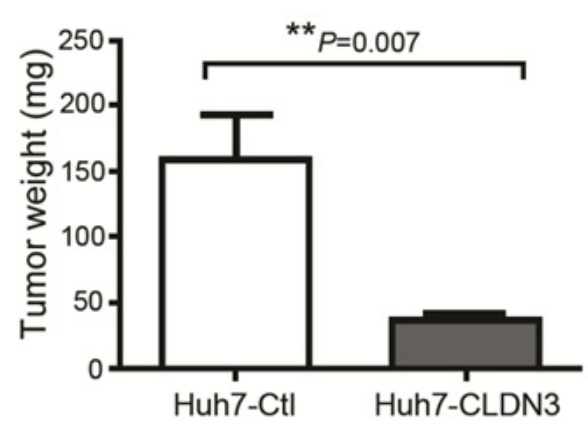

C

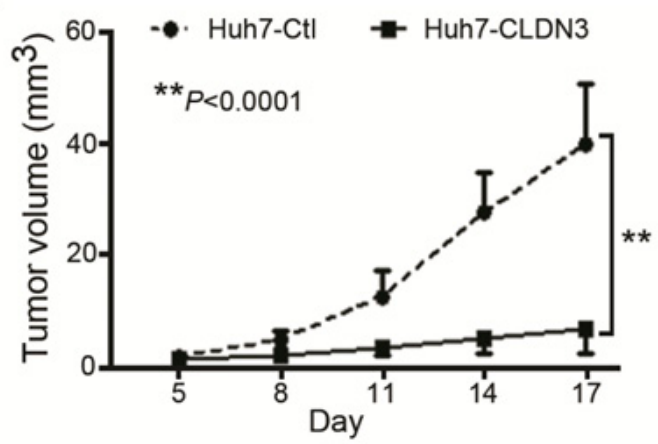

Fig.5: In vivo tumor suppressive role of $C L D N 3$ in HCC. (A) Representative examples of tumors formed in nude mice following injection of CLDN3-expressing Huh7 cells (lower panel) and Huh7-Ctl cells (upper panel). (B) Histogram shows quantitative result of the tumor weight from Huh7-CLDN3 group and control group. Value are mean $\pm \mathrm{SD}$. $\mathrm{P}=0.007$. (C) Tumor growth curves of $C L D N 3$-expressing Huh7 cells (Huh7-CLDN3) in nude mice were compared with Huh7-Ctl cells by tumor xenograft experiment. The average tumor volume of Huh7-CLDN3 cells vs Huh7-Ctl cells was expressed as mean \pm SD in 5 inoculated sites for each group of cells. $* * \mathrm{P}<0.0001$. 
different tissues are highly tissue specific $[25,26]$. CLDN3 was uniformly expressed in the normal rat liver [27] and an increased expression of CLDN3 was observed in liver regeneration 2-3 days after hepatectomy [28], suggesting the potentials of CLDN3 in maintaining normal liver function and regeneration of fully polarized normal hepatocytes. In this study, we observed a cobblestonelike epithelial morphology and cellular aggregation in cultured CLDN3- overexpression HCC cells. In contrast, control HCC cells without endogenous CLDN3 displayed a spindle shape, fibroblast-like mesenchymal morphology, and pronounced cellular scattering in monolayer culture, suggesting the inactivation of $C L D N 3$ in $\mathrm{HCC}$ might be related to EMT and cancer invasion/metastasis. Previous studies reported that morphologic changes from cobblestone-like to fibroblast-like occurred in cells undergoing EMT, which is a key process for epithelial cancer cells to survive following detachment from basement membrane and migrate through the extracellular matrix (ECM) to enable cancer cells to "seed" to adjacent tissues or to colonize to distal part of the body through circulation $[29,30]$. A recent study also demonstrated that both CLDN3 and CLDN4 regulated EMT in ovarian cancer cells [31]. Similar to previous study that CLDN3 has no significant effect on ovarian cancer cell proliferation and cell cycle progression [32], our results also found that ectopic expression of CLDN3 in HCC cells with absent $C L D N 3$ expression did not show any change in the cell proliferation rate, cell cycle distribution, and apoptosis in vitro. However, we observed a significant inhibitory role of $C L D N 3$ in liver cancer cell migration and invasion. Moreover, CLDN3 could significantly inhibit HCC tumor growth in vivo. Notably, overexpression of $C L D N 3$ did not affect cell proliferation in vitro but inhibit tumor growth in vivo. One possibility is that CLDN3 is a transmembrane protein in the tight junction barrier, which may render its growth inhibition potential in vivo in response to extracellular signals originating from the tumor microenvironment. These findings suggested that $C L D N 3$ may play a critical role in maintenance of normal TJ function to prevent cells from dispersion but not in regulation of pathways that determine the cell fate such as cell cycle or apoptosis.

To better elucidate the invasive and metastatic mechanisms of CLDN3, the effect of CLDN3 overexpression or depletion on Wnt signaling pathway and
A

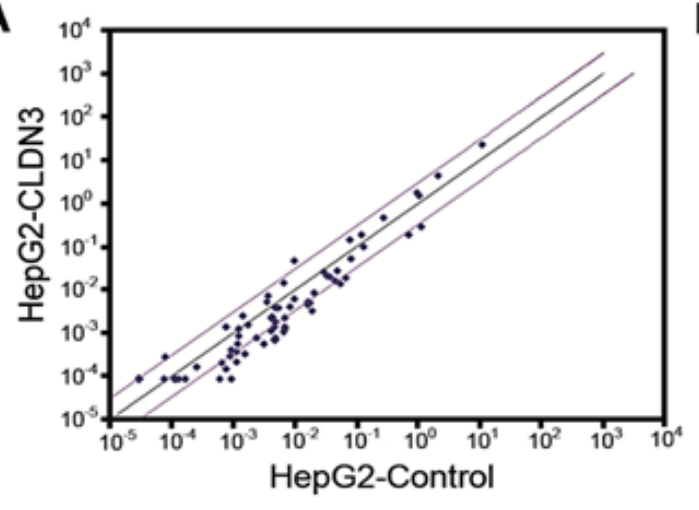

C

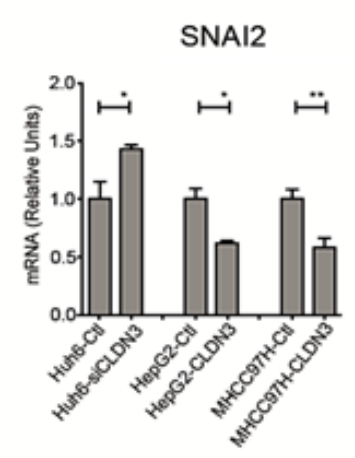

B

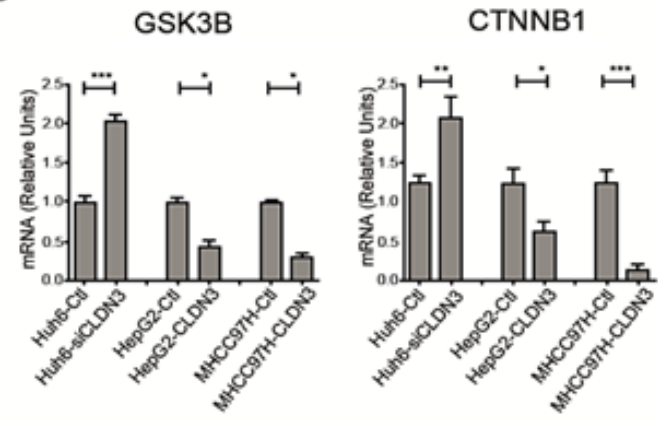

D

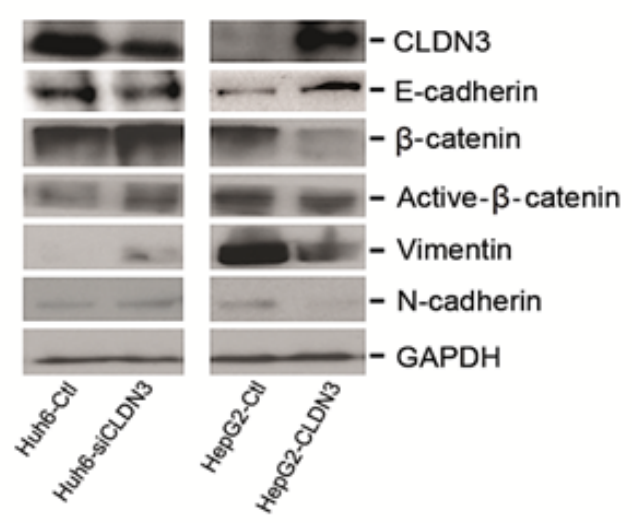

Fig.6: CLDN3 inactivates Wnt-EMT signaling in HCC cells. (A) The scatter plot of PCR array analysis graphs the expression level $\left(2^{-\Delta C t}\right)$ of genes related to Wnt signaling pathway in the HepG2-CLDN3 cells versus the HepG2-Ctl cells. The black line indicates fold changes $\left(2^{-\Delta \Delta \mathrm{Ct}}\right)$ of 1 . The pink lines indicate a fold change of 3 in gene expression. (B, C) Histograms represent the fold up or downregulation of GSK3B and CTNNB1 (B), as well as SNAI2 and CDH2 (C) in CLDN3-overexpression or knockdown HCC cells by qPCR. (D) Expressions of epithelial markers E-cadherin, $\beta$-catenin, active $\beta$-catenin and mesenchymal markers Vimentin and N-cadherin were compared by Western blotting analysis between CLDN3-overexpression or knockdown HCC cells. GAPDH was used as loading control. 
EMT was investigated. Using qPCR analyses, we found the metastasis suppressor role of CLDN3 in HCC cells was associated with the inhibition of Wnt-EMT activity through downregulation of GSK3B (encodes GSK3 $\beta$ ), CTNNB1 (encodes $\beta$-catenin), SNAI2 (encodes Slug), and $\mathrm{CDH} 2$ (encodes N-cadherin) by qPCR analyses. Both GSK3 $\beta$ and $\beta$-catenin are key molecules of the canonical Wnt pathway implied in many human cancers [33]. Although it remains controversial whether GSK3 $\beta$ is a "tumor suppressor" or "tumor promoter" in regulation of neoplastic transformation and tumor progression, GSK3 $\beta$ expression level was found to be higher in liver tumors than in normal liver tissues in a mouse model of hepatic carcinogenesis [34]. A recent study also showed that both GSK $3 \beta$ and $\beta$-catenin expression level were significantly reduced with a concomitant reduction of metastatic capability and expression of Wnt signaling pathway targeted genes in HCC cell line SMMC-7721 subjected to anti-cancer drug treatment [35]. Slug is a critical EMTinducing transcription factor and its activity was also regulated by canonical Wnt signaling [36]. N-cadherin is a mesenchymal marker which can be induced by Slug [37]. Upregulation of $\mathrm{N}$-cadherin is also associated with a heightened invasive potential in many cancers including HCC [38-41]. Further study by western blot analyses confirmed the changes of $\beta$-catenin Slug, N-cadherin in CLDN3 overexpressed or depleted HCC cells. Moreover, the epithelial marker E-cadherin was increased, whereas the mesenchymal marker vimentin was downregulated in CLDN3-overexpressing cells. All of these results postulated that epigenetic silencing of CLDN3 in $\mathrm{HCC}$ might fail to suppress the $\beta$-catenin mediated Wnt pathway to promote EMT.

In conclusion, we demonstrated that CLDN3 is an epigenetically silenced metastasis suppressor gene and plays a crucial role in the development and progression of HCC. CLDN3 downregulation was an independent prognostic factor for poor survival of HCC. A better understanding of the molecular mechanism of CLDN3 in inhibiting liver cancer cell metastasis may lead to a more effective management of $\mathrm{HCC}$ patients with the inactivation of $C L D N 3$.

\section{METHODS}

\section{Cell lines and cell culture}

Ten human HCC cell lines (HepG2, Hep3B, Huh1, Huh6, Huh7, SNU398, SNU449, PLC5, Bel7404, and MHCC97H) were used in this study. Cell lines were maintained in Dulbecco's modified Eagle's medium supplemented with 10\% fetal bovine serum (FBS) and 1\% penicillin-streptomycin.

\section{Patients and tissue samples}

Two cohorts of clinical HCC tissue samples were investigated in this study. Cohort 1 includes 52 pairs of primary HCC tumors and their adjacent nontumorous tissues, which were collected immediately after surgical resection prior to any other therapeutic intervention at the Third Affiliated Hospital of Sun Yat-Sen University (Guangzhou, China). All samples were confirmed by histology. Informed consent was given by all of the patients. The study protocol was approved by the Clinical Research Ethics Committee of the Sun Yat-Sen University of Medical Sciences. Cohort 2 includes cDNA samples synthesized from 114 pairs of primary HCC tumors and their adjacent nontumorous tissues, which were kindly provided by Prof. XY Guan at the University of Hong Kong [42]. Human normal liver tissue RNA samples were purchased commercially (Stratagene, La Jolla, CA). Clinical data of Cohort 2 patients included in this study are detailed in Supplementary Table 1.

\section{RT-PCR and real-time quantitative PCR (qPCR)}

Total RNA was extracted by Direct-zol RNA MiniPrep kit (Zymo Research, Irvine, CA) from cell pellets or tissues. cDNA was synthesised by MultiScribe Reverse Transcriptase (ABI, Calsbad, CA). RT-PCR was performed with TaKaRa Taq Hot Start Version kit (Takara, Japan). Q-PCR was performed with Power SYBR Green PCR Master Mix reagent (ABI). 10ng cDNA template and 3 pmol of primer pairs were applied in each $10 \mu \mathrm{l}$ PCR reaction. All qPCR primers used in this study were acquired from online primer database (medgen.ugent.be) and purchased commercially (Invitrogen, Calsbad, CA).

\section{5-aza-2'-deoxycytidine (5-Aza) treatment}

$1 \times 10^{7}$ cells of each HCC cell line were seeded into $100 \mathrm{~mm}$ culture dishes and incubated overnight. 5-Aza (Sigma, St. Louis, MO) was then added into the cell culture at a final concentration of $2 \mu \mathrm{M}$ and incubated for 96h. After 5-Aza treatment, the cells were harvested for RNA extraction and further analysis.

\section{Bisulfite treatment and promoter methylation analysis}

Genomic DNA was extracted by QIAamp DNA Mini Kit (Qiagen, Valencia, CA) and $1 \mathrm{mg}$ of DNA was bisulfite-modified by EZ DNA Methylation-Gold Kit (Zymo Research) following the manufacturer's instructions. The bisulfite-modified DNA was then amplified by methylation-specific PCR (MSP) using primer pairs that specifically amplify either methylated 
or unmethylated sequences of the CLDN3 gene. Bisulfite genomic sequencing (BGS) was performed to assess the methylation levels of $9 \mathrm{CpG}$ sites spanning from -117 to -2 of the CLDN3 promoter region in HCC cell lines. Nucleotide sequences of the primers were listed in Supplementary Table 2.

\section{CLDN3 cloning and lentivirus transduction}

The full-length CLDN3 cDNA was obtained by RT-PCR using normal human liver cDNA as template. The PCR product was cloned into pcDNA3.1/V5-HisTOPO TA vector (Invitrogen) and the authenticity of the sequence was verified by sequencing (BGI, Shenzhen, China). The pCDNA3.1-CLDN3 plasmid was then subcloned into lentiviral eukaryotic expression vector $\mathrm{pLVX}$ ZsGreen1-PGK-Puro by commercially available service (Genomeditech, Shanghai, China) and the lentivirus particles were packaged by GM easy lentivirus packaging kit (Genomeditech) in 293FT cells and harvested after $48 \mathrm{~h}$ incubation by following the manufacturer's instructions. The lentiviral particles containing either empty vector or CLDN3 construct were transducted into HCC cell lines and the cells were then subjected to puromycin $(2 \mu \mathrm{g} / \mathrm{ml})$ selection for at least 2 weeks to establish stable CLDN3expressing clones.

\section{RNA Interference}

Small interfering RNA (siRNA) (100 nM) against CLDN3 or a scrambled sequence (RiboBio Co. Ltd. Guangzhou, China) was transfected into cells in 6-well plates using jetPRIME transfection reagent (PolyplusTransfection, Illkirch-Graffenstaden, France) according to the manufacturer's instructions. At $48 \mathrm{~h}$ after transfection, the effects of gene silencing were measured via qPCR and western blot analysis.

\section{Foci formation assay}

$1 \times 10^{3}$ of CLDN3-transfected or empty vectortransfected HCC cells were seeded in 6-well plates and selected with puromycin $(2 \mu \mathrm{g} / \mathrm{ml})$ for 7 days. Surviving colonies were then visualized by $1 \%$ crystal violet staining and colonies with no less than 50 cells/colony were counted.

\section{Cell proliferation assay}

Cell proliferation was determined by xCELLigence RTCA DP system (Roche, Kaiseraugst, Switzerland). Briefly, $5 \times 10^{3}$ HCC cells were seeded into each well of the 16-well E-plate supplied by $200 \mu 1$ DMEM culture medium in triplicates. The xCELLigence system was then used to monitor the cell growth rate continuously for $72 \mathrm{~h}$.

\section{Cell cycle and apoptosis analysis}

Cell cycle distribution and apoptosis were examined by flow cytometry. For cell cycle analysis, after $12 \mathrm{~h}$ of synchronization by serum starvation, the CLDN3transfected HCC cells were incubated with $10 \%$ fetal bovine serum (FBS) for $24 \mathrm{~h}$. Cells were fixed in $70 \%$ ethanol and stained with $50 \mu \mathrm{g} / \mathrm{mL}$ propidium iodide (BD Pharmingen, San Jose, CA). The cells were then sorted by FACSCalibur (BD Biosciences, San Jose, CA) and cellcycle profiles were analyzed by WinMDI v. 2.9 software (Scripps Research Institute, La Jolla, CA). Apoptosis was assessed by flow cytometry after staining with FITC conjugated Annexin V and 7-amino-actinomycin (7-AAD) following the manufacturer's instruction (BD Biosciences).

\section{Migration assay and invasion assay}

For cell migration assay, cells were seeded into 24 -well plate $\left(2 \times 10^{5} /\right.$ well $)$ and incubate overnight. After starving in serum free medium for $24 \mathrm{~h}$, the cell layer was wounded using a sterile tip and the medium was then replaced by DMEM containing $10 \%$ FBS. The crosses in the wells were photographed by microscopy at time point 0 hour and 24 hours. The percentages of open wound area were calculated using TScratch software [43] kindly provided by Dr. Johnny Koon at the Chinese University of Hong Kong. The experiment was performed in triplicate. For invasion assay, cells were starved with serum free medium for $24 \mathrm{~h}$ before the assay. Cells $\left(1 \times 10^{5}\right)$ were suspended in $0.5 \mathrm{ml}$ serum-free medium and loaded on the upper compartment of invasion chamber coated with Matrigel (BD Biosciences). The lower compartment was filled with complete medium as chemoattractant. After $24 \mathrm{~h}$, invasive cells were fixed, stained, and counted under a microscope. Triplicate independent experiments were performed.

\section{Immunohistochemistry (IHC)}

IHC staining was performed using the standard streptavidin-biotin-peroxidase complex method. Briefly, paraffin sections of HCC tissues were deparaffinized, blocked with $10 \%$ normal goat serum for $10 \mathrm{~min}$, and incubated with anti-CLDN3 polyclonal antibody (Invitrogen, 1:800 dilution) overnight at $4^{\circ} \mathrm{C}$. The tissue section was then incubated with biotinylated goat antirabbit immunoglobulin at a concentration of $1: 75$ at $37^{\circ} \mathrm{C}$ for $30 \mathrm{~min}$. The status of CLDN3 expression was assessed by two independent investigators without prior knowledge of clinicopathologic data. The extent of CLDN3 staining 
was scored manually by assigning the percentage of positive tumor cells $(0$, none; $1,<40 \%$ of positive staining cells; $2,40-70 \%$ of positive staining cells; $3,>70 \%$ of positive staining cells).

\section{In vivo tumorigenicity}

$1 \times 10^{7}$ of stable CLDN3-overexpression cells and control cells were injected subcutaneously into the dorsal right flank of 6 -week-old male Balb/c nude mice $(n=5$ per group), respectively. Tumor diameter was measured every 3 days from the 5th day after inoculation for 17 days. The tumor volume was calculated by the formula $\mathrm{V}=0.5 \times \mathrm{L} \times \mathrm{W}^{2}$. All experimentations on animals were approved by the Animal Experimentation Ethics Committee of the Chinese University of Hong Kong.

\section{RT2 profiler PCR array}

Total RNA extraction was performed using the Direct-zol RNA MiniPrep kit as described above. The first-strand cDNA synthesis was performed using a $\mathrm{RT}^{2}$ First-Strand cDNA Synthesis kit (Qiagen) and $1000 \mathrm{ng}$ of total RNA was processed for the human WNT signaling pathway PCR array (SABiosciences, PAHS-043Z, Frederick, MD). Alterations in mRNA transcript levels between HepG2-CLDN3 and HepG2-Ctl groups were initially analyzed using SABiosciences webportal software (http://www.sabiosciences.com/pcrarraydataanalysis.php). Fold changes and $P$ values were calculated using Student's t-test. A $P$ value $<0.05$ with a fold change greater than 3.0 were considered to be a significant dysregulation.

\section{Western blot}

Total protein was extracted and the concentrations were determined by Bradford Protein Assay (Bio-Rad, Hercules, CA). $30 \mu \mathrm{g}$ of protein from each sample was separated on $8 \sim 12 \%$ SDS-PAGE and transferred onto polyvinylidene fluoride membrane (Bio-Rad). Blots were detected by incubation with antibodies to CLDN3 (Invitrogen), total/active $\beta$-catenin, E-cadherin, Vimentin, $\mathrm{N}$-cadherin, and GAPDH (Cell Signaling, Danvers, MA).

\section{Statistics}

Statistical analysis was performed with the SPSS standard version 16.0 (Chicago, IL) or GraphPad Prism 5 (GraphPad Software, La Jolla, CA). Results expressed as mean $\pm \mathrm{SD}$ were analyzed using the Student $t$ test. The difference of CLDN3 expression between tumor and adjacent normal tissues were compared using the MannWhitney U test. Correlation between CLDN3 expression and clinicopathological features were determined by
Pearson's Chi-square test. Overall survival curves was assessed by the Kaplan-Meier method and compared by the log-rank test. Relative risks of cancer-related death associated with CLDN3 expression status were estimated by univariate analyses. Multivariate survival analysis was carried out on all parameters that were found to be significant on univariate level using the Cox regression model. $\mathrm{P}$ value less than 0.05 was considered statistically significant.

\section{ACKNOWLEDGEMENTS}

The project was supported by Collaborative Research Fund (CUHK3/CRF/12R; HKU3/CRF11R) of the Research Grant Council Hong Kong; National Basic Research Program of China (973 Program, 2013CB531401); CUHK Focused Investments Scheme B to HY Lan; and Theme-based Research Scheme of the Hong Kong Research Grants Council (T12-403-11).

\section{Disclosure of interest}

The authors declare no conflict of interest.

\section{REFERENCES}

1. El-Serag HB. Hepatocellular carcinoma. N Engl J Med 2011;365:1118-1127.

2. Calvisi DF, Ladu S, Gorden A, Farina M, Lee JS, Conner EA, Schroeder I, Factor VM, Thorgeirsson SS. Mechanistic and prognostic significance of aberrant methylation in the molecular pathogenesis of human hepatocellular carcinoma. J Clin Invest. 2007;117:2713-2722.

3. Nishida N, Goel A. Genetic and epigenetic signatures in human hepatocellular carcinoma: a systematic review. Curr Genomics. 2011; 12:130-137.

4. Pogribny IP, Rusyn I. Role of epigenetic aberrations in the development and progression of human hepatocellular carcinoma. Cancer Lett. 2014; 342:223-230

5. Liu W, Li X, Chu ES, Go MY, Xu L, Zhao G, Li L, Dai N, Si J, Tao Q, Sung JJ, Yu J. Paired box gene 5 is a novel tumor suppressor in hepatocellular carcinoma through interaction with p53 signaling pathway. Hepatology. 2011; 53:843-853.

6. Latorre IJ, Frese KK, Javier RT. Tight junction proteins and cancer. In: Gonzalez-Mariscal L, editor. Tight junctions. New York: Springer US; 2006; p. 116-134.

7. Swift JG, Mukherjee TM, Rowland R. Intercellular junctions in hepatocellular carcinoma. J Submicrosc Cytol. 1983; 15:799-810.

8. Takai E, Tan X, Tamori Y, Hirota M, Egami H, Ogawa M. Correlation of translocation of tight junction protein Zonula occludens-1 and activation of epidermal growth factor receptor in the regulation of invasion of pancreatic 
cancer cells. Int J Oncol. 2005;27:645-651.

9. Martin TA, Jiang WG. Loss of tight junction barrier function and its role in cancer metastasis. Biochim Biophys Acta. 2009; 1788:872-891.

10. Singh AB, Sharma A, Dhawan P. Claudin family of proteins and cancer: an overview. J Oncol. 2010; 2010:541957.

11. Morohashi S, Kusumi T, Sato F, Odagiri H, Chiba H, Yoshihara S, Hakamada K, Sasaki M, Kijima H. Decreased expression of claudin-1 correlates with recurrence status in breast cancer. Int J Mol Med. 2007; 20:139-43.

12. Väre P, Loikkanen I, Hirvikoski P, Vaarala MH, Soini Y. Low claudin expression is associated with high Gleason grade in prostate adenocarcinoma. Oncol Rep. 2008;19:2531.

13. Dhawan P, Singh AB, Deane NG, No Y, Shiou SR, Schmidt C, Neff J, Washington MK, Beauchamp RD. Claudin-1 regulates cellular transformation and metastatic behavior in colon cancer. J Clin Invest. 2005; 115:1765-1776.

14. Choi YD, Kim KS, Ryu S, Park Y, Cho NH, Rha SH, Jang JJ, Ro JY, Juhng SW, Choi C. Claudin-7 is highly expressed in chromophobe renal cell carcinoma and renal oncocytoma. J Korean Med Sci. 2007; 22:305-10.

15. Al Moustafa AE, Alaoui-Jamali MA, Batist G, HernandezPerez M, Serruya C, Alpert L, Black MJ, Sladek R, Foulkes WD. Identification of genes associated with head and neck carcinogenesis by cDNA microarray comparison between matched primary normal epithelial and squamous carcinoma cells. Oncogene. 2002; 21:2634-2640.

16. Kominsky SL, Argani P, Korz D, Evron E, Raman V, Garrett E, Rein A, Sauter G, Kallioniemi OP, Sukumar S. Loss of the tight junction protein claudin-7 correlates with histological grade in both ductal carcinoma in situ and invasive ductal carcinoma of the breast. Oncogene. 2003; 22:2021-2033.

17. Hewitt KJ, Agarwal R, Morin PJ. The claudin gene family: expression in normal and neoplastic tissues. BMC Cancer. 2006; 6:186.

18. Roth MJ, Abnet CC, Hu N, Wang QH, Wei WQ, Green L, D'Alelio M, Qiao YL, Dawsey SM, Taylor PR, Woodson K. p16, MGMT, RARbeta2, CLDN3, CRBP and MT1G gene methylation in esophageal squamous cell carcinoma and its precursor lesions. Oncol Rep. 2006; 15:1591-1597.

19. Honda H, Pazin MJ, D’Souza T, Ji H, Morin PJ. Regulation of the CLDN3 gene in ovarian cancer cells. Cancer Biol Ther. 2007; 6:1733-1742.

20. Hasegawa K, Wakino S, Simic P, Sakamaki Y, Minakuchi H, Fujimura K, Hosoya K, Komatsu M, Kaneko Y, Kanda T, Kubota E, Tokuyama H, Hayashi K, et al. Renal tubular Sirt1 attenuates diabetic albuminuria by epigenetically suppressing Claudin-1 overexpression in podocytes. Nat Med. 2013; 19:1496-1504.

21. Di Cello F, Cope L, Li H, Jeschke J, Wang W, Baylin $\mathrm{SB}$, Zahnow CA. Methylation of the claudin 1 promoter is associated with loss of expression in estrogen receptor positive breast cancer. PLoS One. 2013; 8:e68630.

22. Boireau S, Buchert M, Samuel MS, Pannequin J, Ryan JL, Choquet A, Chapuis H, Rebillard X, Avancès C, Ernst M, Joubert D, Mottet N, Hollande F. DNA-methylationdependent alterations of claudin-4 expression in human bladder carcinoma. Carcinogenesis. 2007; 28:246-258.

23. Hurd TW, Gao L, Roh MH, Macara IG, Margolis B. Direct interaction of two polarity complexes implicated in epithelial tight junction assembly. Nat Cell Biol. 2003; 5:137-142.

24. Thiery JP, Acloque H, Huang RY, Nieto MA. Epithelialmesenchymal transitions in development and disease. Cell. 2009; 139:871-890.

25. Peppi M, Ghabriel MN. Tissue-specific expression of the tight junction proteins claudins and occludin in the rat salivary glands. J Anat. 2004; 205:257-266.

26. Fujita H, Sugimoto $\mathrm{K}$, Inatomi $\mathrm{S}$, Maeda $\mathrm{T}$, Osanai M, Uchiyama Y, Yamamoto Y, Wada T, Kojima T, Yokozaki H, Yamashita T, Kato S, Sawada N, et al. Tight junction proteins claudin-2 and -12 are critical for vitamin D-dependent $\mathrm{Ca} 2+$ absorption between enterocytes. Mol Biol Cell. 2008; 19:1912-1921.

27. Rahner C, Mitic LL, Anderson JM. Heterogeneity in expression and subcellular localization of claudins 2, 3, 4, and 5 in the rat liver, pancreas, and gut. Gastroenterology. 2001; 120:411-422.

28. Takaki Y, Hirai S, Manabe N, Izumi Y, Hirose T, Nakaya M, Suzuki A, Mizuno K, Akimoto K, Tsukita S, Shuin T, Ohno S. Dynamic changes in protein components of the tight junction during liver regeneration. Cell Tissue Res. 2001; 305:399-409.

29. Yu M, Smolen GA, Zhang J, Wittner B, Schott BJ, Brachtel E, Ramaswamy S, Maheswaran S, Haber DA. A developmentally regulated inducer of EMT, LBX1, contributes to breast cancer progression. Genes Dev. 2009; 23:1737-42.

30. Xie G, Yao Q, Liu Y, Du S, Liu A, Guo Z, Sun A, Ruan J, Chen L, Ye C, Yuan Y. IL-6-induced epithelialmesenchymal transition promotes the generation of breast cancer stem-like cells analogous to mammosphere cultures. Int J Oncol. 2012; 40:1171-1179.

31. Lin X, Shang X, Manorek G, Howell SB. Regulation of the Epithelial-Mesenchymal Transition by Claudin-3 and Claudin-4. PLoS One. 2013; 8:e67496.

32. Shang X, Lin X, Alvarez E, Manorek G, Howell SB. Tight junction proteins claudin-3 and claudin-4 control tumor growth and metastases. Neoplasia. 2012; 14:974-985.

33. Korinek V, Barker N, Morin PJ, et al. Constitutive transcriptional activation by a beta-catenin-Tcf complex in APC-/- colon carcinoma. Science 1997; 275:1784-1787.

34. Gotoh J, Obata M, Yoshie M, Kasai S, Ogawa K. Cyclin D1 over-expression correlates with beta-catenin activation, but not with H-ras mutations, and phosphorylation of Akt, GSK3 beta and ERK1/2 in mouse hepatic carcinogenesis. 
Carcinogenesis. 2003; 24:435-442.

35. Luo Y, Sun Z, Li Y, Liu L, Cai X, Li Z. Caudatin inhibits human hepatoma cell growth and metastasis through modulation of the Wnt/ $\beta$-catenin pathway. Oncol Rep. 2013;30:2923-2928.

36. Wu ZQ, Li XY, Hu CY, Ford M, Kleer CG, Weiss SJ. Canonical Wnt signaling regulates Slug activity and links epithelial-mesenchymal transition with epigenetic Breast Cancer 1, Early Onset (BRCA1) repression. Proc Natl Acad Sci U S A. 2012; 109:16654-16659.

37. Shirley SH, Greene VR, Duncan LM, Torres Cabala CA, Grimm EA, Kusewitt DF. Slug expression during melanoma progression. Am J Pathol. 2012; 180:2479-2489.

38. Islam S, Carey TE, Wolf GT, Wheelock MJ, Johnson KR. Expression of $\mathrm{N}$-cadherin by human squamous carcinoma cells induces a scattered fibroblastic phenotype with disrupted cell-cell adhesion. J Cell Biol. 1996; 135: 1643 1654.

39. Hazan RB, Phillips GR, Qiao RF, Norton L, Aaronson SA. Exogenous expression of $\mathrm{N}$-cadherin in breast cancer cells induces cell migration, invasion, and metastasis. J Cell Biol. 2000; 148: 779-790.

40. Nakajima S, Doi R, Toyoda E, Tsuji S, Wada M, Koizumi M, Tulachan SS, Ito D, Kami K, Mori T, Kawaguchi Y, Fujimoto K, Hosotani R, et al. N-cadherin expression and epithelial-mesenchymal transition in pancreatic carcinoma. Clin Cancer Res. 2004; 10:4125-4133.

41. Fan M, Liu Y, Xia F, Wang Z, Huang Y, Li J, Wang Z, Li $X$. Increased expression of EphA2 and E-N cadherin switch in primary hepatocellular carcinoma. Tumori. 2013; 99:689696.

42. Li Y, Chen L, Chan TH, Liu M, Kong KL, Qiu JL, Li Y, Yuan YF, Guan XY. SPOCK1 is regulated by CHD1L and blocks apoptosis and promotes HCC cell invasiveness and metastasis in mice. Gastroenterology. 2013; 144:179-191.

43. Gebäck T, Schulz MM, Koumoutsakos P, Detmar M. TScratch: a novel and simple software tool for automated analysis of monolayer wound healing assays. Biotechniques. 2009; 46:265-274. 